\title{
Kinetic and equilibrium study of the chromatographic separation of glycine and ammonium
}

\author{
Lihua Jiang ${ }^{1}$, Huiyuan Liu', Yongjun Qiu', Yaosong Wang ${ }^{1}$, Chaoqin Chen ${ }^{1}$, Qifan Wang ${ }^{2}$ and Liming Zhao ${ }^{\text {1* }}$
}

\begin{abstract}
Background: Glycine is extensively applied in the field of food, medicine, agrochemistry, etc. It is usually commercially produced by the chemosynthesis method, which generates large amounts of by-product ammonium chloride.

Methods: In this paper, the separation of glycine and ammonium chloride was performed with chromatographic column, and deionized water as eluent. The adsorption equilibrium constant $K$ of glycine and ammonium chloride was evaluated by frontal analysis. Based on the equilibrium-dispersive model and a linear driving force of chromatography, the overall mass transfer coefficient $k_{m}$, axial dispersion coefficient $D_{L}$, and bed voidage $\varepsilon_{t}$ of the column were obtained by moment analysis.

Results: At $50^{\circ} \mathrm{C}$, the equilibrium constants measured were found to be 0.72 and 0.19 for glycine and ammonium chloride, respectively. At $60^{\circ} \mathrm{C}$, the equilibrium constants increased to 0.80 and 0.21 for glycine and ammonium chloride, respectively. The value of axial dispersion coefficient $D_{L}$ of glycine had the same order of magnitude with ammonium chloride and was about two times larger than that of ammonium chloride. Their $k_{m}$ at $50^{\circ} \mathrm{C}$ and $60^{\circ} \mathrm{C}$ were 1.30 and 0.77 and 2.41 and $0.84 \mathrm{~min}^{-1}$ for glycine and ammonium chloride, respectively.

Conclusions: The obtained parameters used to simulate the elution curve and the simulation and experimental results matched well, which showed that the parameters obtained were effective. The results make foundation for further study on large-scale separation of glycine from ammonium chloride by SMB chromatography.
\end{abstract}

Keywords: Glycine; Ammonium chloride; Equilibrium; Kinetics; Chromatography; Simulation

\section{Background}

Glycine, known as amino acetic acid, is an important intermediate chemical product [1], extensively applied in medicine, agrochemical, food, fertilizer, animal feed, and related industries. With the rising demands for glycine, more attention was paid to its production process and separation technology. Glycine is commercially produced by $\alpha$-halogenated, chloroacetic acid and ammonia as raw materials, which generate glycine with by-product ammonium chloride [2]. Compared with other production processes, it is cost-effective, easy to operate, and environment-friendly $[3,4]$. However, the recovery of glycine from the mixtures is not straightforward. Some

\footnotetext{
* Correspondence: zhaoliming@ecust.edu.cn

'State Key Laboratory of Bioreactor Engineering, R\&D Center of Separation and Extraction Technology in Fermentation Industry, East China University of Science and Technology, Shanghai 200237, China

Full list of author information is available at the end of the article
}

researchers used recrystallization, ion exchange, and electrodialysis methods to separate and purify glycine from the mixture solution [4]. Unfortunately, because of many chemicals and energy consumption, these methods are neither economic nor environment-friendly.

Chromatography technology has been developed as one of the major separation processes in general and especially simulated moving bed (SMB), which has been successfully applied in the food industry especially in the sugar industry [5-8].

To our knowledge, no research on chromatographic separation of the glycine and ammonium chloride has been previously reported by now. In this work, the separation of glycine and ammonium chloride was performed with chromatographic column, deionized water used as eluent solution, and results showed that the separation efficiency was quite high. In this paper, our purpose is focused on the

\section{实}

(c) 2014 Jiang et al.; licensee Springer. This is an Open Access article distributed under the terms of the Creative Commons Attribution License (http://creativecommons.org/licenses/by/2.0), which permits unrestricted use, distribution, and reproduction in any medium, provided the original work is properly cited. 
study of the mass transfer kinetics and equilibrium of the separation of glycine and ammonium chloride, in order to apply this technology to an industrial scale for separation of glycine from salts by SMB chromatography. In this study, based on the equilibrium-dispersive model of chromatography, overall mass transfer coefficients together with the axial dispersion coefficients were experimentally determined by moment analysis. Meanwhile, some parameters obtained were used to simulate the elution profiles, and simulation and experimental results were compared.

\section{Theories}

The equilibrium-dispersive model of chromatography

Lots of theories and models have been proposed for describing liquid chromatography mathematically with various equilibrium and mass transfer parameters. In this work, the equilibrium-dispersive model was used to present the chromatographic process. Therefore, the mass balance equation for each component in the mobile phase can be written as [9]

$$
\frac{\partial c_{i}}{\partial t}+F \frac{\partial q_{i}}{\partial t}+v \frac{\partial c_{i}}{\partial z}=D_{L} \frac{\partial^{2} c_{i}}{\partial z^{2}}
$$

where $c_{i}$ and $q_{i}$ are the concentrations (component $i$ ) in the mobile phase and the stationary phase, respectively, $F$ is the phase ratio and it is related to the total column porosity $\varepsilon_{t},\left(F=\frac{1-\varepsilon_{t}}{\varepsilon_{t}}\right), v$ is the velocity of interstitial mobile phase, $D_{L}$ represents the axial dispersion coefficient, $t$ is the time, and $z$ is the space coordinates.

For a linear driving force approximation,

$$
\frac{\partial q}{\partial t}=k\left(q^{*}-q\right)
$$

where $k$ is the mass transfer coefficient, $q^{*}$ is the equilibrium concentration of stationary phase, and the solution of concentration $c_{i}$ is given by the linear isotherm of Equation 3 .

$$
q^{*}=K_{i} c_{i}
$$

$K_{i}$ represents the equilibrium constant of component $i$, Equation 2 supposes the driving force of the mass transfer of $q_{i}{ }^{*}$ is different with $q_{i}$ and the mass transfer rate will increase with the driving force increasing. This linear driving force expression supposes that the main resistance in the particle diffusion step can be described by an overall mass transfer coefficient.

\section{Moment analysis}

The method of moment analysis, used to describe the hydrodynamic characteristics, has been considered as the effective means to determine axial dispersion coefficient $D_{L}$ and mass transfer parameters in pulse experiments [10-14]. As we all know, the experimental first $\left(\mu_{1}\right)$ and second $\left(\mu_{2}\right)$ moments are the average retention time and variance, respectively, which can be written as

$$
\begin{aligned}
& \mu_{1}=\frac{L}{V}\left[1+\left(\frac{1-\varepsilon_{T}}{\varepsilon_{T}}\right) K\right] \\
& \mu_{2}=\frac{2 L}{v}\left\{\frac{D_{l}}{v^{2}}\left[1+\left(\frac{1-\varepsilon_{T}}{\varepsilon_{T}}\right) K\right]^{2}+\left(\frac{1-\varepsilon_{T}}{\varepsilon_{T}}\right) \frac{K}{k_{m}}\right\}
\end{aligned}
$$

The first and second moments can deduce the height equivalent to a theoretical plate (HETP).

$$
\begin{aligned}
& \text { HETP }=\frac{L}{N}=\frac{\mu_{2} L}{\mu_{1}{ }^{2}}=\frac{2 D_{L}}{v}+2 v\left(\frac{\varepsilon_{T}}{1-\varepsilon_{T}}\right) \frac{1}{K k_{m}} \\
& {\left[1+\left(\frac{\varepsilon_{T}}{1-\varepsilon_{T}}\right) \frac{1}{K}\right]^{-2} } \\
& N=5.545\left(\frac{t_{R}}{w_{1 / 2}}\right)^{2}
\end{aligned}
$$

where $L$ is the column length, $N$ is the theoretical plate number, $w_{1 / 2}$ is the peak width at half height, $k_{m}$ is the overall mass transfer coefficient, and $K$ is the equilibrium constant. Equation 6 implies that axial dispersion cannot be calculated by a simple linear regression because of its nonlinear relationship with HETP.

It is assumed that axial dispersion is influenced by two different mechanisms, among which one is molecular diffusion in the axial direction and the other is an eddy mixing term proportional to the fluid velocity. Therefore, the expression for the axial dispersion coefficient $D_{L}$ is

$$
D_{L}=\eta D_{m}+\lambda v
$$

where $D_{m}$ is the molecular diffusivity, $v$ is the interstitial velocity, $\eta$ is the tortuosity factor for a packed column, and $\lambda$ is a constant dependent on flow geometry. In the liquid system, the molecular diffusivities are so small that Equation 8 can be simplified as [15]

$$
D_{L}=\lambda v
$$

Substituting Equation 9 into Equation 6,

$$
\mathrm{HETP}=2 \lambda+2 v\left(\frac{\varepsilon_{T}}{1-\varepsilon_{T}}\right) \frac{1}{K k_{m}}\left[1+\left(\frac{\varepsilon_{T}}{1-\varepsilon_{T}}\right) \frac{1}{K}\right]^{-2}
$$

In Equations 6 and 10, the overall mass transfer resistance $\left(1 / k_{m}\right)$ in theory contains three separate mass transfer mechanisms (the external film resistance, intraparticle diffusion resistance, and adsorption/desorption resistance). It is commonly assumed that the kinetics of adsorption/desorption are rapid. If we ignore the influence 
of adsorption/desorption resistance to the overall mass transfer resistance, the following relation between the film mass transfer and the lumped mass transfer coefficient and intraparticle diffusion coefficients can be represented by [16]

$$
\frac{1}{k_{m}}=\frac{d_{p}}{6 k_{f}}+\frac{d_{p}{ }^{2}}{60 D_{p}}
$$

where $d_{p}$ is particle diameter and $k_{f}$ and $D_{p}$ are the external film mass transfer coefficient and the pore diffusion coefficient, respectively. To us all, a function of liquid velocity can represent the external film mass transfer coefficient. When the liquid systems satisfy the condition of $0.0015<\operatorname{Re}<55, k_{f}$ could be acquired by the Wilson and Geankoplis correlation [17].

$$
\mathrm{Sh}=\frac{k_{f} d_{p}}{D_{m}}=\frac{1.09}{\varepsilon_{b}} \mathrm{Sc}^{\frac{1}{3}} \operatorname{Re}^{\frac{1}{3}}
$$

In general, $k_{f}$ is larger than $D_{p}$, at least a few orders of magnitude, which had been confirmed by some researchers [18] at similar chromatographic systems. Thus, the influence of external film resistance can be negligible and $k_{m}$ will not depend on liquid velocity in this study. It is clear that Equation 11 can be simplified as

$$
\frac{1}{k_{m}}=\frac{d_{p}^{2}}{60 D_{p}}
$$

From Equation 13, $k_{m}$ can be considered as a constant which is independent of liquid velocity. Therefore, the overall mass transfer coefficient $k_{m}$ can be determined by the first and second moments.

\section{Methods}

\section{Materials and equipment}

Blue dextran with MW 2,000,000 kg/ $\mathrm{kmol}$ was acquired from Sigma-Aldrich Co. (St. Louis, MO, USA). Ammonium chloride (purity $\geq 99 \%$ ), glycine (purity $\geq 99 \%$ ), and acetone was purchased from Lingfeng Chemical Reangent Co. (Shanghai, China). The sample mixture of glycine and ammonium chloride was provided by Hainan Zhengye Zhongnong High-Tech Co., Ltd. (Hainan, China). Pocket refractometer was a product of ATAGO (Tokyo, Japan). The resin elected in experiments is a novel tailor-made cation exchange resin, which is water-insoluble and reticular. All other chemicals were of analytical or highperformance liquid chromatography (HPLC) grade.

\section{Semi-preparative chromatographic system}

The system [19] is used to measure the hydrodynamics and thermodynamic model parameters, i.e., column porosity, axial dispersion, coefficient, and adsorption isotherms. It includes a glass-jacketed column $(30 \times 1.6 \mathrm{~cm}$ I.D. $)$, circulating water bath $\mathrm{MP}-5 \mathrm{H}$ (bought from Yiheng Technical Co., Shanghai, China), a fraction collector (FRC-10A), and pump BT100 (purchased from Huxi Analysis Instrument Factory Co, Shanghai, China).

\section{Analytical method}

The single component solutions (samples), i.e., with concentrations over $10 \mathrm{~g} / \mathrm{L}$ were analyzed by the refractometer [19]. Below this concentration, the analysis was performed with a standard titration method, from Chinese standard about determination of glycine and ammonium chloride (GB 25542-2010), to measure the glycine and the ammonium chloride concentration.

\section{Experimental procedures}

Initially, a glass column was filled with elected resin. The flow rate was fixed at $1.0 \mathrm{~mL} / \mathrm{min}$ with the total mixture concentration of about $10 \mathrm{~g} / \mathrm{L}$. The experiments were carried out at $30^{\circ} \mathrm{C}$.

\section{Bed porosities}

The moment analysis was used for determination of bed porosities. The residence time distribution (RTD) curves were determined from tracer experiments [20]. The blue dextran $(2 \mathrm{~g} / \mathrm{L})$ and acetone $(20 \% v / v)$ as the mobile phase were performed for assessing external $(\varepsilon)$ and total $\left(\varepsilon_{t}\right)$ bed void fractions, respectively. The experiments were carried out at $1.0 \mathrm{~mL} / \mathrm{min}$ and $50^{\circ} \mathrm{C}$. The profiles recorded were used to calculate bed porosities.

\section{Adsorption isotherms}

Frontal analysis method [20,21] was used to determine the single component adsorption isotherms of glycine and ammonium chloride. The glycine concentration was in a range between 25 and $180 \mathrm{~g} / \mathrm{L}$, and ammonium chloride concentration was between 25 and $200 \mathrm{~g} / \mathrm{L}$. The flow rates were around $1 \mathrm{~mL} / \mathrm{min}$ for glycine and ammonium chloride. The glycine or ammonium chloride (single component) solution was pumped into the column for enough time so as to saturate it completely. For each glycine (or ammonium chloride) liquid phase concentration, three experiments were performed and the average value of the equilibrium concentration in the liquid and solid phases were calculated and used in the presentation of the singlecomponent adsorption isotherm. The experiments were performed at $50^{\circ} \mathrm{C}$ and $60^{\circ} \mathrm{C}$.

In equilibrium, the concentration of the stationary phase $q_{i}$ * was obtained by mass balance, which can be expressed as

$$
q_{i}^{*}=\frac{A_{i}-\varepsilon v_{c}}{(1-\varepsilon) v_{c}}
$$


Where $A_{i}=\int_{0}^{\infty}\left[C_{0}-C_{i}(t)\right] d_{t}-C_{0} t_{\text {dead }}$ The $t$ dead is the dead time, which is the space time in the extra column volumes (tubing, connections, and pump heads) of the experimental setup. $C_{0}$ represents the feeding concentration; $\varepsilon$ and $C(t)$ are the porosity of the resin and the tracer concentration at the exit of the column, respectively. $V_{c}$ is the column volume.

\section{Axial dispersion and mass transfer coefficients}

In the semi-preparative chromatographic system, the experiments were carried out at five different rates (1.0 to $3.0 \mathrm{~mL} / \mathrm{min})$ and at different temperatures $\left(50^{\circ} \mathrm{C}\right.$ and $\left.60^{\circ} \mathrm{C}\right)$. The profiles recorded were used to determine axial dispersion and mass transfer coefficients [13].

\section{Results and discussion}

The pulses of a dilute solution of mixture were injected into the column filled with chromatography resin. Figure 1 is the typical chromatography of separation of glycine and ammonium chloride. Obviously, the resin performed well as shown in Figure 1, in which glycine completely separated from ammonium chloride. Therefore, this resin is chosen to conduct continual experiments.

\section{Determination of porosity}

The blue dextran and acetone tracers were detected by UV at wavelengths 630 and $310 \mathrm{~nm}$, respectively. Because the blue dextran's molecules are unable to penetrate into the pores of the stationary phase, the first moment of the blue dextran peak allowed calculating the external porosity $\varepsilon$ (see Equation 15), which can also be written as [20]:

$$
\mu=\frac{\int_{0}^{\infty} t \cdot C(t) d t}{\int_{0}^{\infty} C(t) d t}=\frac{\varepsilon V_{c}}{Q}
$$

where $C(t)$ is the concentration of blue dextran or acetone at the exit of the column, $V_{c}$ is the column volume, $\mu$ is the time of the peak moment. By injecting acetone as tracer and applying Equation 15, it is possible to estimate the total bed porosity since acetone is small enough to penetrate both in the interparticle voids in the bed and also those inside the resin particles, the internal porosity of the resin, $\varepsilon_{P}$ may be calculated from Equation 16.

$$
\varepsilon_{T}=\varepsilon+(1-\varepsilon) \varepsilon_{P}
$$

The tracer elution profile at the column, as shown in Figure 2, could be calculated by Equation 14. The retention time of blue dextran and acetone was 27.5 and $59.0 \mathrm{~min}$, respectively. The external porosity $\varepsilon$ determined from the blue dextran was 0.42 . The value of total porosity $\varepsilon_{t}$ was 0.89 . According to Equation 16 , the internal porosity of the resin $\varepsilon_{P}$ was 0.82 . These parameter values from the above fitted in the range of typical resin porosity values.

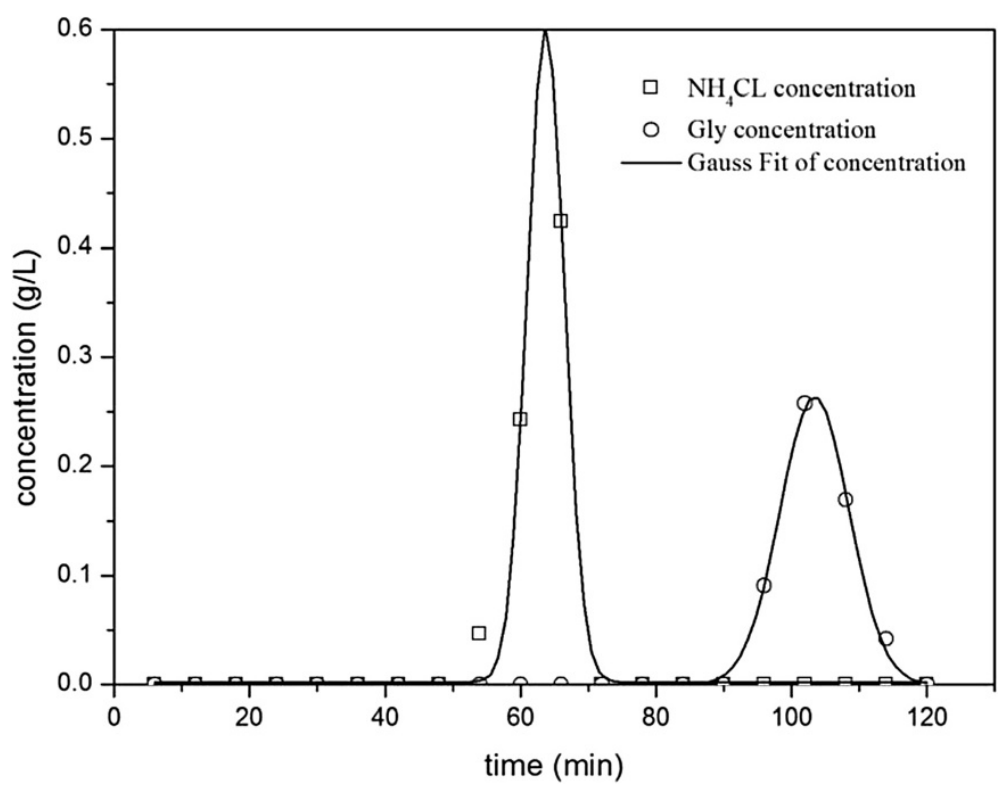

Figure 1 Typical chromatogram of separation about glycine and ammonium chloride. The less-retained compound is ammonium chloride and the more-retained compound is glycine. Experiment condition: mixture concentration $10 \mathrm{~g} / \mathrm{L}$; flow rate $1 \mathrm{~mL} / \mathrm{min}$; mobile phase, deionized water; temperature $30^{\circ} \mathrm{C}$. 


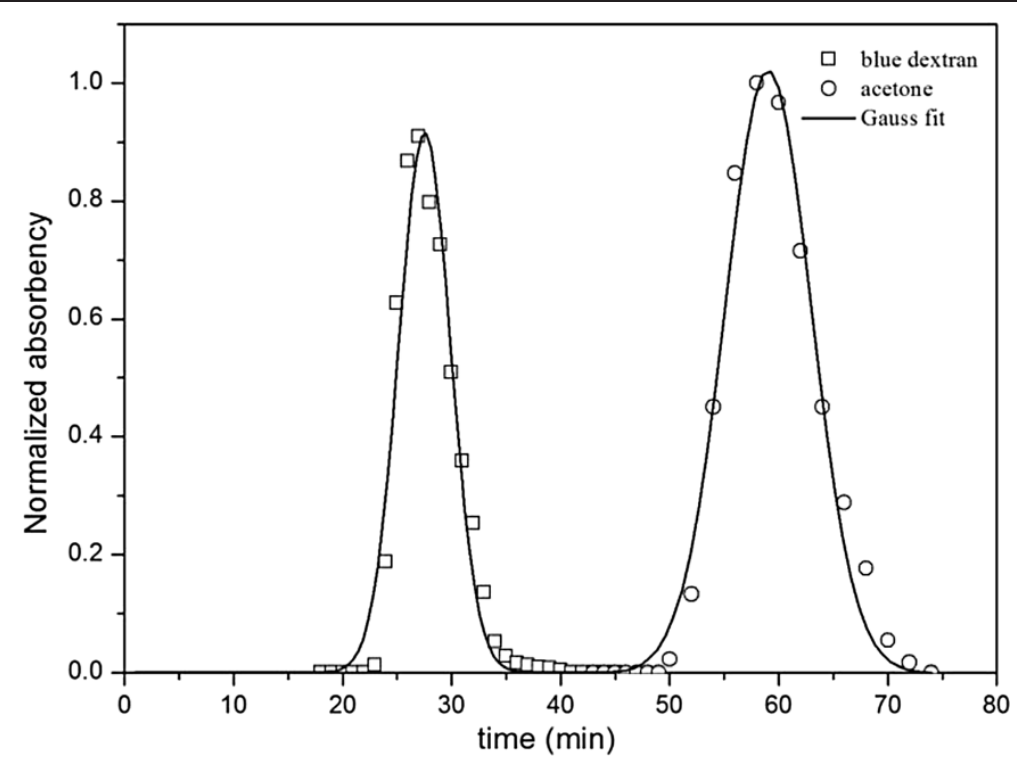

Figure 2 Typical elution profiles of the blue dextran and acetone. The less-retained compound is blue dextran and the more-retained compound is acetone.

\section{Determination of the adsorption equilibrium constant}

The equilibrium adsorption isotherms of glycine and ammonium chloride, as obtained by frontal analysis of single component synthetic solutions, were illustrated in Figures 3 and 4. Figures show the relationship between the concentration of glycine and ammonium chloride on the mobile phase and stationary phase at $50^{\circ} \mathrm{C}$ and $60^{\circ} \mathrm{C}$. The experimental data was fitted by linear function. As demonstrated in Figures 3 and 4, the experimental data correlated well with the linear regression. The slopes of each line distinguished the $K$ values. The linear equations, $R^{2}$ values and the adsorption equilibrium constant for each series of experiments were listed in Table 1. It was observed that the equations and $R^{2}$ values were in good agreement with the experimental data. According to Table 1, it could be concluded that the $K$ values of glycine were higher than those of ammonium chloride, and their values increased as the temperature increased.

In fact, sorption is an exothermic process [22]. With the increase in temperature of the adsorbate-adsorbent

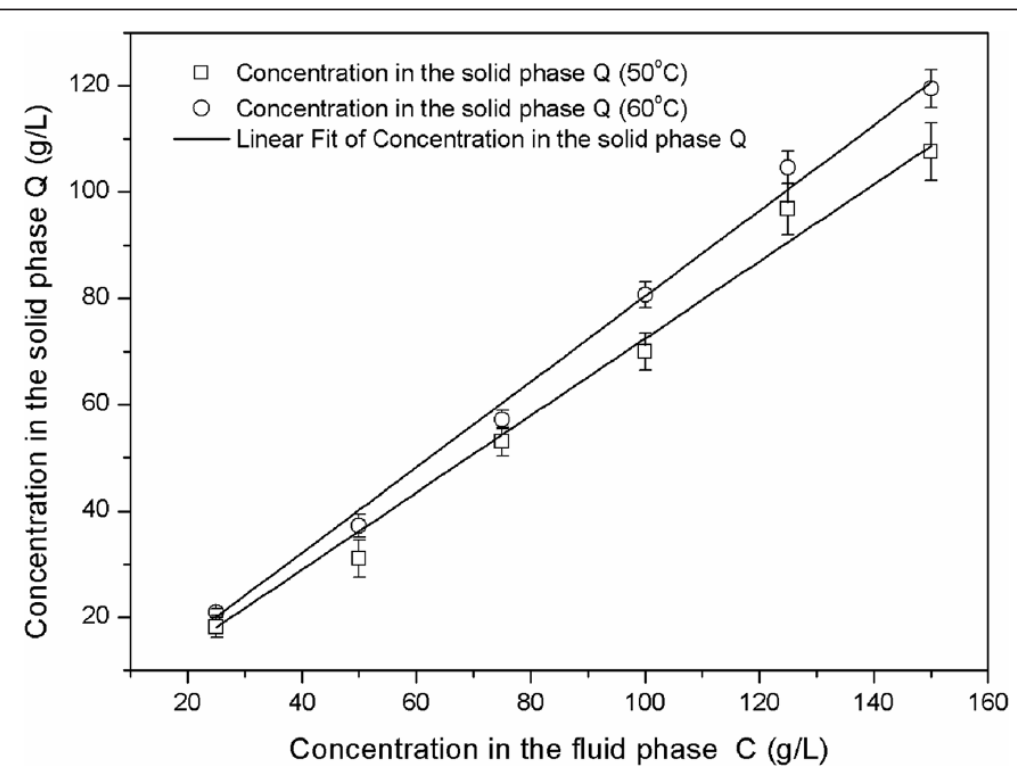

Figure 3 Adsorption isotherms of glycine at $50^{\circ} \mathrm{C}$ and $60^{\circ} \mathrm{C}$. 


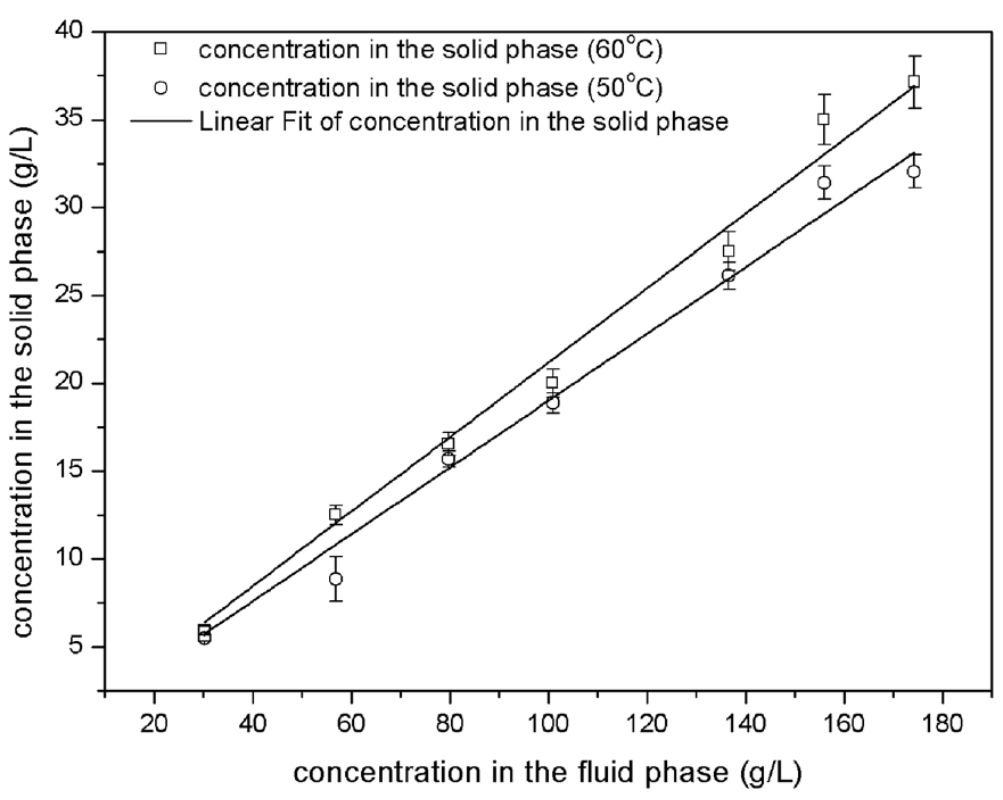

Figure 4 Adsorption isotherms of ammonium chloride at $50^{\circ} \mathrm{C}$ and $60^{\circ} \mathrm{C}$.

system, the sorption decreases. In other words, the adsorption equilibrium constant will decrease with the increase in temperature. However, when the diffusion process (intra-particle or transport-pore diffusion) mainly controls the adsorption process, the sorption capacity will increase with the increase in temperature. This is basically due to the fact that the diffusion process is an endothermic process, which leads to increasing the sorptive capacity of the adsorbent. Therefore, the increase of sorption capacity with the increase of temperature maybe attributed to the diffusion process.

\section{Determination of axial dispersion and mass transfer coefficients}

The following assumption was considered: the kinetics of adsorption-desorption was infinitely fast. On the basis of Equation 10, it is obvious that the HETP has a close relationship between the axial dispersion and the mass transfer resistance. HETP for glycine and ammonium chloride should increase linearly with velocity. As shown in Figures 5 and 6, plots of HETP for glycine and ammonium chloride versus interstitial velocity of mobile phase gave the intercept $2 \lambda$ and the slope was related to the

Table 1 Equilibrium isotherms for glycine and ammonium chloride

\begin{tabular}{cccccc}
\hline $\mathbf{T} /{ }^{\circ} \mathrm{C}$ & \multicolumn{2}{c}{ Glycine } & & \multicolumn{2}{c}{$\mathbf{N H}_{\mathbf{4}} \mathrm{Cl}$} \\
\cline { 2 - 3 } \cline { 5 - 6 } & Adsorption isotherm & $\boldsymbol{R}^{\mathbf{2}}$ & & Adsorption isotherm & $\boldsymbol{R}^{\mathbf{2}}$ \\
\hline 50 & $Y=0.72 X$ & 0.9970 & & $Y=0.19 X$ & 0.9976 \\
60 & $Y=0.80 X$ & 0.9988 & & $Y=0.21 X$ & 0.9971 \\
\hline
\end{tabular}

overall mass transfer coefficient $k_{m}$. The overall mass transfer coefficients could be calculated by the slope of straight lines, and their values were listed in Table 2. The value of axial dispersion coefficient $D_{L}$ of glycine had the same order of magnitude with that of ammonium chloride and was about two times larger than that of ammonium chloride. What is more, compared with ammonium chloride, the overall mass transfer coefficient $k_{m}$ inside the particles of glycine was obviously larger. For ammonium chloride, the axial dispersion coefficient $D_{L}$ and the overall mass transfer coefficient $k_{m}$ showed a slight discrepancy at different temperatures, but showed an apparent change with those for glycine. These results about different trends in $k_{m}$ between glycine and ammonium chloride would be due to the different kinetics of adsorption and desorption processes, which we should study in the future.

\section{Modeling of the chromatograms with determined parameters}

In order to test the effectiveness of parameters determined from the above study, the model parameters about the total column porosity $\varepsilon_{T}$, axial dispersion coefficient $D_{L}$, equilibrium constants $K$, and over-all mass transfer coefficients $k_{m}$ were used to simulate the elution profiles. The corresponding initial conditions for Equations 1 and 2 are given by

$$
c_{i}(t=0, z)=0
$$

Boundary condition at the column inlet

$$
c_{i}(t=0, z)=c_{i}^{0}, \text { for } 0<t \leq t_{p}
$$




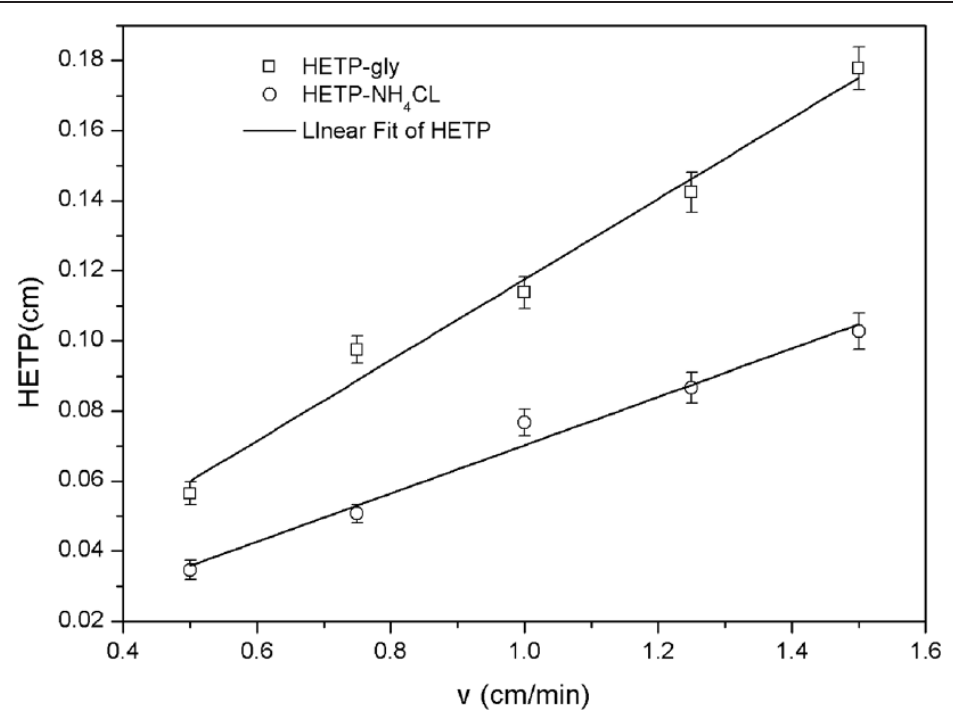

Figure 5 Plot of HETP of glycine and ammonium chloride versus the interstitial velocity of mobile phase at $50^{\circ} \mathrm{C}$.

$$
c_{i}(t=0, z)=0, \text { for } t>t_{p}
$$

Boundary condition at the column outlet

$$
\left.\frac{\partial c_{i}(t, z)}{\partial \mathrm{z}}\right|_{Z=L}=0
$$

To obtain the calculated band profiles, we used the method of lines (MOL) to solve Equations 1 and 2 through the initial and boundary conditions. The partial differential equations Equations 1 and 2 were discretized by the finite difference method (FDM) into a set of ordinary differential equations (ODEs) [23]. A MATLAB program was used to solve the resultant ODEs of the initial value problems.
The simulated results were shown in Figure 7. There was a slight difference, but the simulated and experimental results matched well in peak shapes. It confirmed that the parameters achieved in this paper were all effective. These parameters are useful for future simulation and design of operating conditions for preparative chromatography.

\section{Conclusions}

The separation of the glycine and ammonium chloride was achieved by the chromatography method. The overall mass transfer coefficient $k_{m}$, axial dispersion coefficient $D_{L}$, and bed voidage of the column were successfully determined by moment analysis and the adsorption

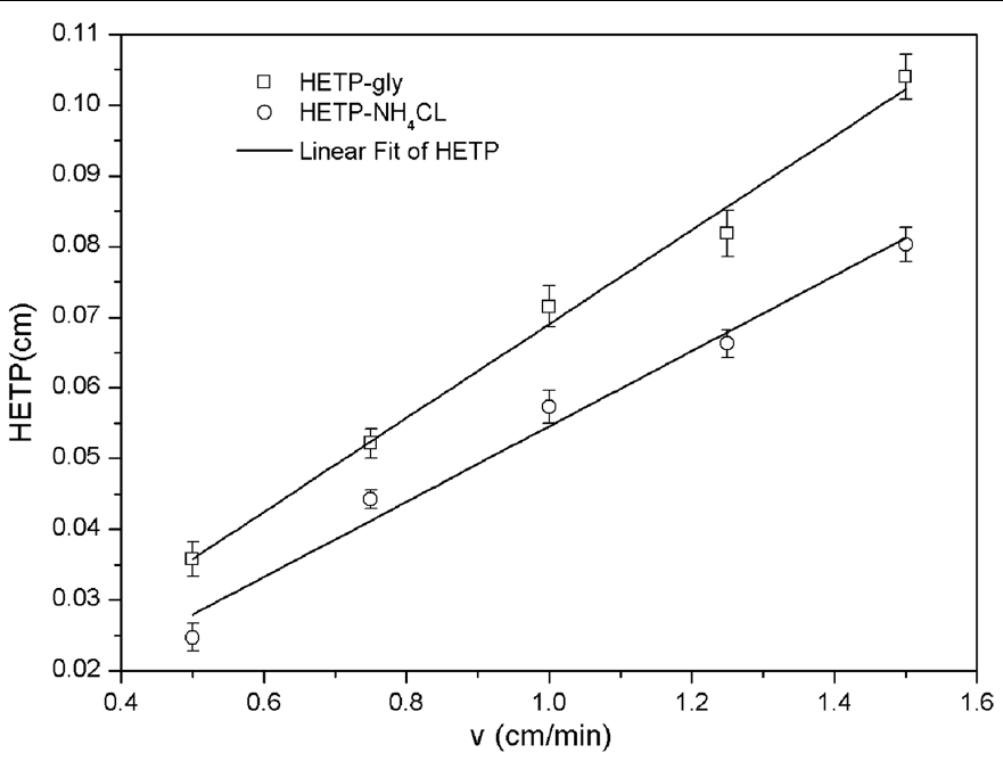

Figure 6 Plot of HETP of glycine and ammonium chloride versus the interstitial velocity of mobile phase at $60^{\circ} \mathrm{C}$. 
Table 2 Axial dispersion and mass transfer coefficients

\begin{tabular}{|c|c|c|c|c|c|c|}
\hline \multirow[t]{2}{*}{$\overline{\mathrm{T} /{ }^{\circ} \mathrm{C}}$} & \multicolumn{3}{|c|}{ Glycine } & \multicolumn{3}{|c|}{$\mathrm{NH}_{4} \mathrm{Cl}$} \\
\hline & $K$ & $\begin{array}{c}D_{L} \times 10^{3} \\
\left(\mathrm{~cm}^{2} / \mathrm{min}\right)\end{array}$ & $K_{m}\left(\min ^{-1}\right)$ & $\bar{K}$ & $\begin{array}{c}D_{L} \times 10^{3} \\
\left(\mathrm{~cm}^{2} / \mathrm{min}\right)\end{array}$ & $K_{m}\left(\min ^{-1}\right)$ \\
\hline 50 & 0.72 & $1.23 \mathrm{~V}$ & 1.30 & 0.19 & $0.64 v$ & 0.77 \\
\hline 60 & 0.80 & $1.30 \mathrm{~V}$ & 2.41 & 0.21 & $0.65 v$ & 0.84 \\
\hline
\end{tabular}

equilibrium constant $K$ of glycine and ammonium chloride were obtained by frontal analysis. The value of axial dispersion coefficient $D_{L}$ of glycine was about two times larger than that of ammonium chloride, and $k_{m}$ inside the particles of glycine was also larger than that of ammonium chloride. What is more, the values of $k_{m}$ and $D_{L}$ were increased with an increase in temperature, which would be a reason to explain the increase in adsorption equilibrium constant $K$ with the increase in temperature. These parameters obtained were tested by simulation of the elution profiles, and the simulation results
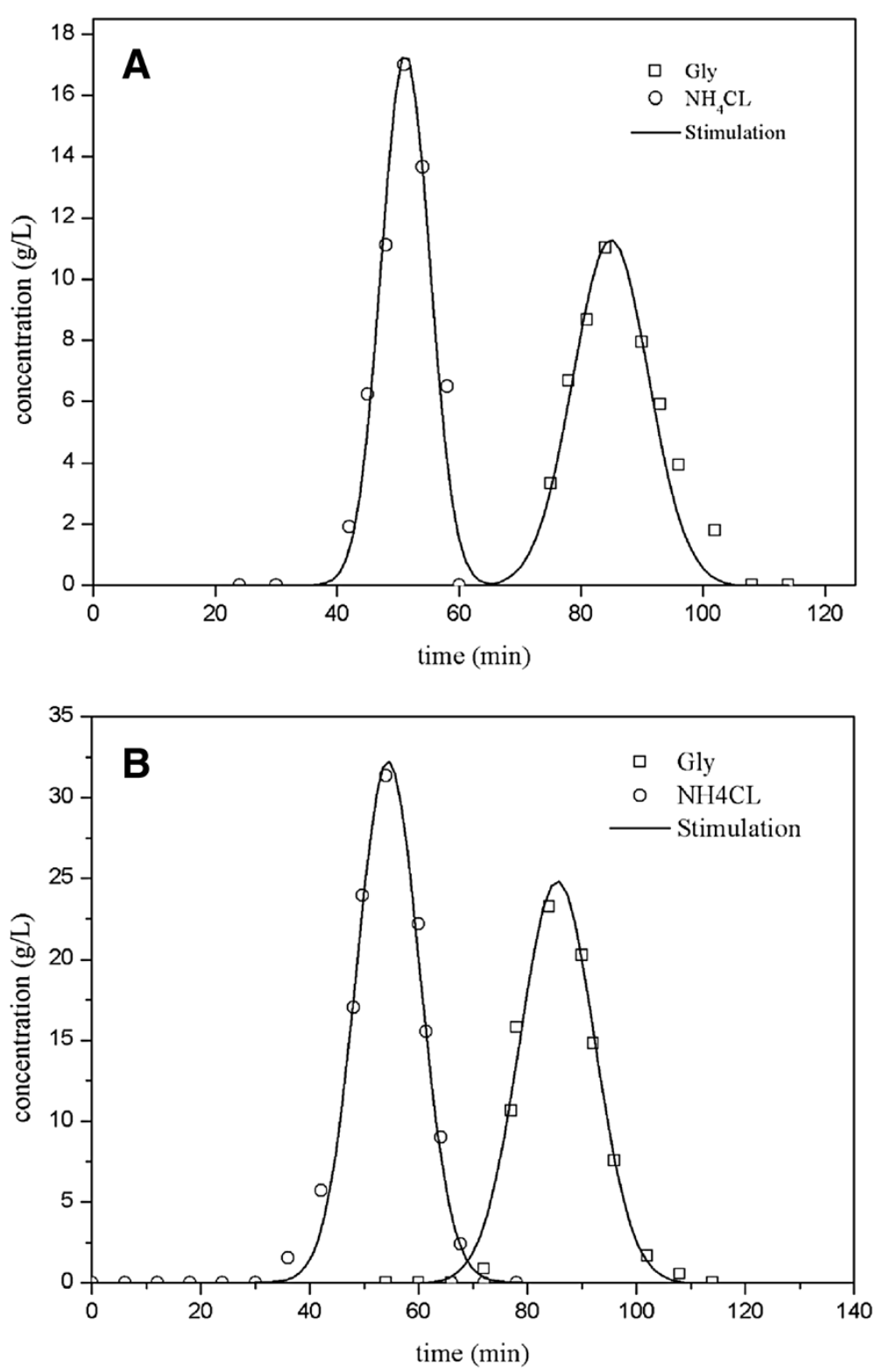

Figure 7 Comparison of the simulated and experimental elution profiles of glycine and ammonium chloride. (A) Experiment condition: mixture concentration $100 \mathrm{~g} / \mathrm{L}$; flow rate $1.5 \mathrm{~mL} / \mathrm{min}$; mobile phase, deionized water; temperature $50^{\circ} \mathrm{C}$. (B) Experiment condition: mixture concentration $150 \mathrm{~g} / \mathrm{L}$; flow rate $1.0 \mathrm{~mL} / \mathrm{min}$; mobile phase, deionized water; temperature $60^{\circ} \mathrm{C}$. 
fitted the experimental results very well. The reported results will be used in the optimization of preparative chromatography such as SMB chromatography after the determination of the adsorption isotherms in later work for a large scale.

\section{Abbreviations}

$c_{i}$, concentration of component $i$ in mobile phase $(\mathrm{g} / \mathrm{L}) ; c_{i 0}$, concentration of inlet $(\mathrm{g} / \mathrm{L}) ; D_{L}$, axial dispersion coefficient $\left(\mathrm{cm}^{2} / \mathrm{s}\right) ; D_{m}$, molecular diffusion coefficient $\left(\mathrm{cm}^{2} / \mathrm{s}\right) ; D_{p}$, pore diffusion coefficient $\left(\mathrm{cm}^{2} / \mathrm{s}\right) ; F$, phase ratio; HETP, height equivalent to a theoretical plate $(\mathrm{cm}) ; k_{f}$ external film mass transfer coefficient $(\mathrm{cm} / \mathrm{min}) ; k_{m}$, overall mass transfer coefficient $\left(\mathrm{min}^{-1}\right) ; K$, equilibrium constant; $L$, column length $(\mathrm{cm}) ; N$, theoretical plate number; $q_{i}$, concentration of component $i$ on stationary phase $(\mathrm{g} / \mathrm{L}) ; q_{i}^{*}$, equilibrium concentration of component $i$ on stationary phase $(\mathrm{g} / \mathrm{L}) ; \mathrm{Q}$, flow rate of mobile phase $(\mathrm{mL} / \mathrm{min}) ; \mathrm{Re}$, Reynolds number; Sc, Schmidt number; Sh, Sherwood number; $t$, time coordinate; $t_{0}$, retention time of unretained compound ( $\mathrm{min}) ; t_{R}$, retention time of enantiomer ( $\left.\mathrm{min}\right) ; u$, superficial fluid velocity $(\mathrm{cm} / \mathrm{min}) ; v$, interstitial fluid velocity $(\mathrm{cm} / \mathrm{min}) ; V_{c}$, column volume $\left(\mathrm{cm}^{3}\right) ; w_{1 / 2}$, peak width at half height; $z$, space coordinate; $\varepsilon_{b}$, bed voidage; $\varepsilon_{t}$, total column porosity; $\eta$, tortuosity factor; $\lambda$, flow geometrydependent constant; $\mu_{1}$, first moment; $\mu_{2}$, second moment.

\section{Competing interests}

The authors declare that they have no competing interests.

\section{Authors' contributions}

L, HL and QW carried out the experiment and participated in calculation of Modeling of the chromatograms. YQ, YW and CC mainly contributed to draft and polish the manuscript. All authors read and approved the final manuscript.

\section{Authors' information}

LJ earned her B.Sc. at Xinjiang University, China in 1992 and obtained her M. S. and Ph.D. under the supervision of Prof. Kikue Kubota at Otyanomizu University, Japan in 2000 and 2003, respectively. As a researcher at Asahi Beer Ltd., Japan (2003-2009), she was engaged in research on the functional food material such as tea and apple. Currently, she is working as an associate professor in the Food Science and Technology Department at East China University of Science and Technology, Shanghai, China. Her research interests include the food flavor analysis, purification and structure elucidation of food active ingredients, functional evaluation, etc.

$\mathrm{HL}$ received her B.Sc. in food science and technology in 2011 from Northeast Forestry University, China. She is currently a M.S. graduate student in food science under the supervision of Prof. Lihua Jiang at East China University of Science and Technology, China. She researches on glycine desalination by chromatography and mass transfer mechanism.

LZ received his M.S. and Ph.D. Degrees in Food Science at Jiangnan University, and he previously earned a B.S. in Food Science and Technology at Wuxi University of Light Industry. He worked in enterprises as R and D leader and General Manager for more than 8 years (2002 to 2010). From 2010, he works as an associate professor in food science and technology and fermentation engineering at East China University of Science and Technology, China. During this period, he worked with Prof. Ruihong Zhang and Zhongli Pan as visiting associate professor at University of California, Davis (2013 to 2014). His research focuses on separation and extraction of bioactive compounds in natural products and fermentation broth, Chitin and Protein, functional food for special diet, separation technology and equipment.

\section{Acknowledgement}

This work was financially supported by the National High Technology Research \& Development Program of China (863 Program) (No. 2014AA021202).

\section{Author details}

${ }^{1}$ State Key Laboratory of Bioreactor Engineering, R\&D Center of Separation and Extraction Technology in Fermentation Industry, East China University of Science and Technology, Shanghai 200237, China. ${ }^{2}$ College of Mechanical and Electrical Engineering, Beijing University of Chemical Technology, Beijing 100029, China.

Received: 22 February 2014 Accepted: 31 March 2014

Published online: 22 April 2014

\section{References}

1. Liang C (2002) Progress and market analysis on glycine synthetic technology. J SiChuan Chem Corrosion Contr 5(3):38-41. doi:10.3969/j.issn.1672-4887.2002.03.004 (in Chinese)

2. Huiling W, Chongbo L, Ruihong D, Jishen L, Shaohua H (2000) A high rate preparation method of glycine. J NanChang Univ (nat sci) 24(3):295-297. doi:10.3969/j.issn.1006-0464.2000.03.018 (in Chinese)

3. Hao CHEN, Xue-mei LI, Chang-feng LI (2010) Study on recycling methanol as medium to produce glycine. Fine Spec Chem 10:56-57. doi:10.3969/j.issn.1008-1100.2010.10.015 (in Chinese)

4. Bouchard A, Hofland GW, Witkamp G-J (2007) Solubility of glycine polymorphs and recrystallization of $\beta$-glycine. J Chem Eng Data 52(5):1626-1629. doi:10.1021/je700014k

5. Al Eid SM (2006) Chromatographic separation of fructose from date syrup. Int J Food Sci Nutr 57(1-2):83-96. doi:10.1080/09637480600658286

6. Bubnik Z, Pour V, Gruberova A, Starhova H, Hinkova A, Kadlec P (2004) Application of continuous chromatographic separation in sugar processing. J Food Eng 61(4):509-513, doi:http://dx.doi.org/10.1016/S0260-8774(03)00221-8

7. Saari P, Heikkilä H, Hurme M (2010) Adsorption equilibria of arabinose, fructose, galactose, glucose, mannose, rhamnose, sucrose, and xylose on ion-exchange resins. J Chem Eng Data 55(9):3462-3467. doi:10.1021/je100165V

8. Pedruzzi I, da Silva EAB, Rodrigues AE (2008) Selection of resins, equilibrium and sorption kinetics of lactobionic acid, fructose, lactose and sorbitol. Sep Purif Technol 63(3):600-611, doi:http://dx.doi.org/10.1016/j.seppur.2008.07.001

9. Shirazi DG, Felinger A, Katti AM (2006) Fundamentals of preparative and nonlinear chromatography. Academic Press, Boston

10. Wang X, Liu Y, Ching CB (2006) Kinetic and equilibrium study of enantioseparation of propranolol in preparative scale chromatography. Sep Purif Technol 50(2):204-211. doi:10.1016/j.seppur.2005.11.027

11. Yu HW, Ching CB (2001) Kinetic and equilibrium study of the enantioseparation of fluoxetine on a new beta-cyclodextrin column by high performance liquid chromatography. Chromatographia 54(11-12):697-702. doi:10.1007/bf02492486

12. Suzuki M (1990) Adsorption engineering. Kodansha, Tokyo

13. Bao Z, Su B, Ren Q (2008) Kinetic and equilibrium study of the enantioseparation of paroxetine intermediate on amylose and tartaric acidbased chiral stationary phases. J Sep Sci 31(1):16-22

14. Skrdla P, Robertson R, Antonucci V, Lindemann C (2003) Chromatographic behavior of ion pair enantiomers of dansyl leucine cyclohexylammonium salt on a $\beta$-cyclodextrin stationary phase and the effect of a competitivebinding mobile phase additive. J Chromatogr Sci 41(3):117-122

15. Ching CB, Arlt W, Lisso M, Wozny G (2000) Kinetic and equilibrium study of the enantioseparation of fenoprofen in a batch setup. Ind Eng Chem Res 39(11):4365-4369. doi:10.1021/ie990219q

16. da Silva IJ, dos Santos MAG, de Veredas V, Santana CC (2005) Experimental determination of chromatographic separation parameters of ketamine enantiomers on MCTA. Sep Purif Technol 43(2):103-110. doi:10.1016/j.seppur.2004.10.009

17. Wilson E, Geankoplis C (1966) Liquid mass transfer at very low Reynolds numbers in packed beds. Ind Eng Chem Fund 5(1):9-14

18. Silva IJ Jr, Santos MAG, Veredas V, Santana CC (2005) Experimental determination of chromatographic separation parameters of ketamine enantiomers on MCTA. Sep Purif Technol 43(2):103-110, doi:http://dx.doi.org/10.1016/j.seppur.2004.10.009

19. Wu J, Peng Q, Arlt W, Minceva M (2009) Model-based design of a pilot-scale simulated moving bed for purification of citric acid from fermentation 
broth. J Chromatogr A 1216(50):8793-8805, doi:http://dx.doi.org/10.1016/j. chroma.2009.03.028

20. Luz DA, Rodrigues AKO, Silva FRC, Torres AEB, Cavalcante CL Jr, Brito ES, Azevedo DCS (2008) Adsorptive separation of fructose and glucose from an agroindustrial waste of cashew industry. Bioresour Technol 99(7):2455-2465, doi:http://dx.doi.org/10.1016/j.biortech.2007.04.063

21. Khosravanipour Mostafazadeh A, Sarshar M, Javadian S, Zarefard MR, Amirifard Haghighi Z (2011) Separation of fructose and glucose from date syrup using resin chromatographic method: experimental data and mathematical modeling. Sep Purif Technol 79(1):72-78, doi:http://dx.doi.org/10.1016/j.seppur.2011.03.014

22. Srivastava VC, Swamy MM, Mall ID, Prasad B, Mishra IM (2006) Adsorptive removal of phenol by bagasse fly ash and activated carbon: equilibrium, kinetics and thermodynamics. Colloids Surf A Physicochem Eng Asp 272(1):89-104

23. Wouwer AV, Saucez P, Schiesser WE, Thompson S (2005) A MATLAB implementation of upwind finite differences and adaptive grids in the method of lines. J Comput Appl Math 183(2):245-258, doi:http://dx.doi.org/ 10.1016/j.cam.2004.12.030

doi:10.1186/s40643-014-0001-0

Cite this article as: Jiang et al:: Kinetic and equilibrium study of the

chromatographic separation of glycine and ammonium. Bioresources and Bioprocessing 2014 1:1.

\section{Submit your manuscript to a SpringerOpen ${ }^{\circ}$ journal and benefit from:}

- Convenient online submission

- Rigorous peer review

- Immediate publication on acceptance

- Open access: articles freely available online

- High visibility within the field

- Retaining the copyright to your article

Submit your next manuscript at $\gg$ springeropen.com 